\title{
Synthesis of 1,2,6-Thiadiazin 1,1-Dioxide Derivatives as Trypanocidal Agents
}

\author{
H. Cerecetto ${ }^{1}$, R. Di Maio ${ }^{1}$, G. Seoane ${ }^{1}$, C. Ochoa $^{2}$, A. Gómez-Barrio ${ }^{3}$ and S. Muelas ${ }^{3}$ \\ ${ }^{1}$ Cátedra de Química Orgánica, Facultad de Química, Universidad de la República General Flores \\ 2124, Montevideo, Uruguay \\ ${ }^{2}$ Instituto de Química Médica (C.S.I.C.), Madrid, Spain \\ ${ }^{3}$ Departamento de Parasitología, Facultad de Farmacia, Universidad Complutense, Madrid, Spain
}

\begin{abstract}
It describes the synthesis of new 1,2,6-Thiadiazin 1,1-dioxide derivatives using condensation of the Knoevenagel type. The products are evaluated in vitro as trypanocidal agents.
\end{abstract}

\section{Introduction}

We have previously reported the synthesis of three series of new compounds and the biological evaluation against Trypanosoma cruzi of 1,2,6-Thiadiazin 1,1-dioxide derivatives, structurally related to Nifurtimox [1,2]. The in vitro assay showed that some of them exhibit significant activity against epimastigote forms of $T$. cruzi, but the cytotoxicity of this type of compounds against Vero cells was highest than the reference drug.

\section{Experimental}

In this work we design new structures, changing the free radical generator.

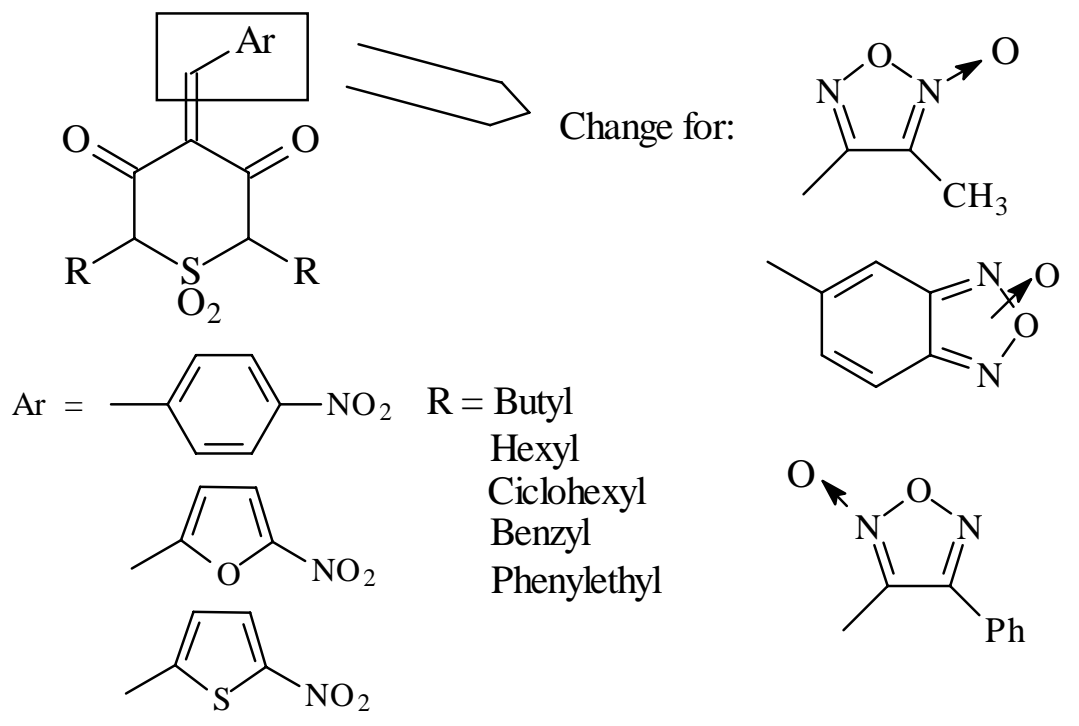


All the compounds were prepared according to the following synthetic pathway

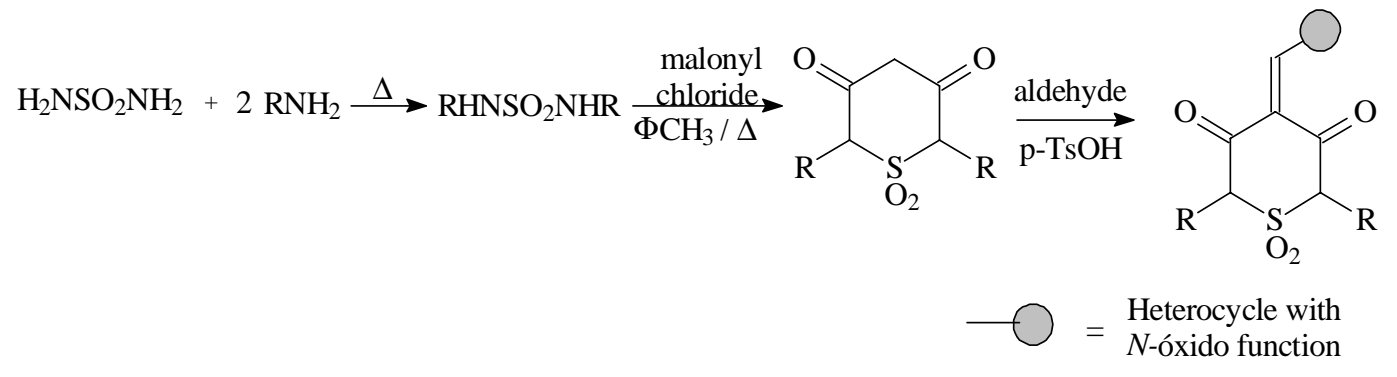

\section{Results and Discussion}

All the compounds have been obtained with good yields, and have been characterized by IR, ${ }^{1} \mathrm{H}-$ $\mathrm{NMR},{ }^{13} \mathrm{C}-\mathrm{NMR}$ and MS.

All the products were tested in vitro against $T$. cruzi epimastigote forms and that more promising were tested their cytotoxicity.

Acknowledgements: The authors thank CYTED (Ciencia y Tecnología para el desarrollo) and RELAQ (Red Latinoamericana de Ciencia Química).

\section{References and Notes}

1. Synthesis and antichagasic properties of new 1,2,6-Thiadiazin-3,5-dione 1,1-dioxides, $\mathrm{XV}^{\text {th }} \mathrm{IN}$ TERNATIONAL SYMPOSIUM ON MEDICINAL CHEMISTRY, 6 al 10 de setiembre de 1998, Edimburgo.

2. Synthesis and antichagasic properties of new 1,2,6-Thiadiazin-3,5-dione 1,1-dioxides and related compounds. Arzneimittel Ferschung (in press). 